\title{
Incidence of Post Dural Puncture Headache and Associated Factors Following Spinal Anaesthesia for Caesarean Delivery in Mulago National Referral Hospital
}

\section{Philo Nambooze}

Makerere University College of Health Sciences

\section{Kizito Samuel}

Makerere University College of Health Sciences

John Baptist Kiggundu ( $\nabla$ jbkiggundu5@gmail.com )

Makerere University College of Health Sciences https://orcid.org/0000-0003-4838-0834

\section{Andrew Kintu}

Makerere University College of Health Sciences

\section{Mary T. Nabukenya}

Makerere University College of Health Sciences

\section{Research article}

Keywords: spinal anesthesia, post dural puncture headache, caesarean section

Posted Date: May 7th, 2019

DOI: https://doi.org/10.21203/rs.2.9491/v1

License: (c) (i) This work is licensed under a Creative Commons Attribution 4.0 International License. Read Full License 


\section{Abstract}

Background Spinal anaesthesia is a cost effective anaesthesia technique commonly used for abdominal procedures like caesarean sections. The incidence of post dural puncture headaches (PDPH) which is one of the most reported complications) remains unknown in Uganda. We set out to study the incidence of PDPH and associated factors following spinal anaesthesia in mothers delivering by caesarean section in Mulago National Referral Hospital. Methods Prospective cohort study among 1294 women that received spinal anaesthesia for emergency caesarean section delivery from July 2015 to February 2016. Consecutive sampling was applied to recruit participants. Pre-tested interviewer administered questionnaires were used to collect information on demographics and associated factors. Both bivariate and multivariate logistic regressions were used with a $P$ value of 0.05 and confidence interval of $95 \%$ being considered statistically significant. Results The incidence of PDPH was found to be $48.8 \%$ $(n=239 / 1294)(95 \% \mathrm{Cl}: 46.0-51.6)$. Significant factors associated with PDPH were history of spinal anaesthesia OR $1.395 \% \mathrm{Cl}(1.0-1.6) \mathrm{p}=0.04$ and loss more than $500 \mathrm{mls}$ of blood during surgery OR 2.2, $95 \% \mathrm{Cl}(1.1-4.2) \mathrm{P}=0.02$. Conclusion Results from our study indicate high incidence of PDPH women undergoing spinal anesthesia for Caesarean section. Prior exposure to spinal anesthesia and blood loss of more than $500 \mathrm{mls}$ are the major associated factors. There is need to objectively screen women at risk for PDPH prior to caesarean section and institute appropriate interventions.

\section{Background}

For a long time general anaesthesia was considered the technique to be used for women undergoing caesarean sections (1). However, the complications attributed to general anaesthesia among pregnant population including but not limited to aspiration of gastric contents, failed intubation, and awareness from the reduced drug doses for fear of sedating the neonate (2), necessitated a change in the anaesthesia technique. Hence, the birth of the growing trend towards regional anaesthetic techniques with available options being spinal and epidural anaesthesia (3).

Spinal anesthesia is widely used in the African setting because of its relatively low cost, effectiveness and reliability in comparison to epidural anaesthesia (4). The advantage of allowing patients to stay alert shortens the time in between surgeries allowing hospitals in low income settings like Mulago National Referral Hospital (MNRH) that delivers 33,000 mothers annually (according to a report by Lewis in 2012) to manage the overwhelming patient numbers. Unfortunately, the spinal anaesthetic technique has been reported to be associated with the complication of post dural puncture headache (PDPH) especially in the obstetric population. The characteristic pain best described by August Bier in 1898 using a personal experience $(5,6)$, increases a mother's suffering which may restrict the patient's acceptance to this anaesthetic technique and prolong hospital stay $(7,8)$.

Studies done in Aga khan University Hospital , Nairobi, Aminu Kano Teaching Hospital, Kano, Nigeria, show a general incidence ranging from 3\% to $60 \%$ (9-11). However there is a paucity of data about PDPH in the obstetric population in our setting. As stated in a study by Jabbari et al (12), "identification 
of factors that predict the likelihood of PDPH is important to ensure measures to minimize this painful complication resulting from spinal anaesthesia" thereby reducing mothers' suffering and shortening their hospital stay. Therefore we set out to study the predictors of post dural puncture headache among women delivering by caesarean section at Mulago national referral hospital.

\section{Methods}

Study design and study setting- we conducted a prospective cohort study among pregnant women who underwent spinal anaesthesia for a caesarean section at Mulago National Referral Hospital. The hospital is located north of Kampala city in Kawempe Division. The hospital serves as the teaching hospital for Makerere University College of Health Sciences. It has a capacity of about 1500 beds and estimated 33,000 deliveries per year with an estimate of 15-20 per day deliveries by caesarean.

Study population-We conducted this study among patients scheduled for emergency caesarean sections. They were recruited and consented to be part of the study.

Sample size estimation Using the Kish Leslie's formula and the incidence of $24.2 \%$ according to a study done in Nairobi (9) ,the estimated sample size was 1205. Sample size for associated factors was used with a $10 \%$ loss to follow up being taken into consideration.

Pre-operative information Trained study assistants would then use a pre-tested questionnaire to gather the patient's demographic information and telephone contacts. Upon entering the operating room, patients were positioned in supine position with a left lateral tilt and their baseline blood pressure, mean arterial pressure, heart rate and oxygen saturation documented. The spinal anaesthetic was delivered by the anaesthesia providers who included anaesthetic officers, residents and anaesthesiologists. The study variable included indication of the caesarean section, anaesthesia provider's level of training, any opioid added to the anaesthetic drug, number of attempts at dural puncture, the lowest blood pressure documented, level of puncture, total volume and type of fluid administered and estimated volume of blood lost during the caesarean section. Needle gauge and size was standardized with a 25 gauge Quincke needle being used.

Post-surgery follow up Study participants were followed up at twenty four hours, 72 hours and on day 7 via phone call. Information about presence of a PDPH, total intravenous, and oral fluids intake were recorded. Participants who developed PDPH were managed with intravenous fluids and a combination of paracetamol and caffeine tablets prescribed for them in addition to the analgesia (diclofenac or tramadol) they were receiving. The patients that developed headache after day three were encouraged to increase their oral intake, have rest, and go to a health center nearest to them for assessment and further management.

Data management and analysis Data was generated in a data base and doubled entered into Epidata version 3.1.1 cleaned and exported to STATA 12 for analysis. Categorical variables were summarized as frequencies and proportions, while continuous variables were summarized using measures of central 
tendancy. In the bivariate analysis, odds ratios with $95 \%$ confidence interval $(\mathrm{Cl})$ were used to measure the association between PDPH and associated factors. All the factors that had a p value of 0.2 and below were included in a multivariate model.

Multivariate analysis using logistic regression was used to determine the factors that were independently associated with PDPH p-value $<0.05$ was considered for statistical significance.

\section{Results}

Baseline characteristics: A total of 1294 parturients scheduled for caesarean section were recruited. The mean age was 26 years SD 5.7, with a range from 16 to 41 years.

Of all the participants, $934(72.2 \%)$ had the anaesthetic administered by anaesthetic officers, $293(22.6 \%)$ by residents and $67(5.6 \%)$ by anaesthesiologists. The main indication for caesarean section was obstructed labour in $520(40.4 \%)$, followed by previous caesarean section with $346(26.9 \%)$. Over thirty two per cent $(n=425)$ patients had been exposed to spinal anaesthesia prior to admission and $10.7 \%$ reported history of a PDPH. Details are highlighted as shown in table 1.

Table 1: Showing pre-operative clinical characteristics for women delivering by caesarean section at Mulago hospital. 


\begin{tabular}{|c|c|}
\hline Variable & $\mathrm{N}$ (percentage) \\
\hline Age (years) & $26.0 \pm 5.7$ \\
\hline \multicolumn{2}{|l|}{ Indication for caesarean section } \\
\hline Obstructed labour & $520(40.4)$ \\
\hline $\mathrm{APH}$ & $35(2.7)$ \\
\hline CPD & $53(4.1)$ \\
\hline Previous scar & $346(26.9)$ \\
\hline Others 1 & $334(25.9)$ \\
\hline \multicolumn{2}{|l|}{ ASA classification } \\
\hline Class 1 & $999(77.2)$ \\
\hline Class 2 & $286(22.1)$ \\
\hline Class 3 and above & $9(0.7)$ \\
\hline History of spinal anaesthesia & $425(32.84)$ \\
\hline History of PDPH & 138(10.7) \\
\hline History of migraines & $21(1.6)$ \\
\hline \multicolumn{2}{|l|}{ Level of insertion* } \\
\hline L3/L4 & 1098(84.9) \\
\hline L4/L5 & 194(15) \\
\hline \multicolumn{2}{|l|}{ Angle of insertion } \\
\hline Oblique & $171(13.2)$ \\
\hline Perpendicular & 1123(86.8) \\
\hline \multicolumn{2}{|l|}{ Number of attempts } \\
\hline Less than 2 & 1118(86.5) \\
\hline More than 2 & 174(13.47) \\
\hline \multicolumn{2}{|l|}{ Anaesthetic drug used } \\
\hline Bupivacaine & 1293(99.9) \\
\hline Lignocaine & $1(0.1)$ \\
\hline \multicolumn{2}{|l|}{ Additive drugs } \\
\hline Fentanyl & $42(37.5)$ \\
\hline
\end{tabular}


Chronic illness

\begin{tabular}{ll}
\hline Hypertension & $6(0.5)$ \\
\hline Others2 & $100(7.7)$ \\
\hline Medication & $126(9.7)$ \\
\hline History of Alcohol & $12(0.9)$ \\
\hline History of Smoking & $3(0.2)$ \\
\hline Body mass index & $28.7 \pm 5.0$ \\
\hline Mean arterial pressure & $96.8 \pm 13.6$ \\
& 13.6 \\
\hline Pulse rate & $101.6 \pm 17.4$ \\
& 17.4 \\
\hline Temperature(0C) & $36.8 \pm 0.4$ \\
\hline Sp02 (\%) & 0.4 \\
\hline
\end{tabular}

*L stands for lumbar , BMI=( mass/height2

Incidence of PDPH: The incidence of post dural puncture headache on the first post-operative day was 14.9(13.0-16.9) while on the third post-operative day, the incidence of PDPH was 20.6(18.2-23.1). The incidence on day seven was 20.6(18.2-23.1). The overall incidence of post dural puncture headache was found to be $48.8(\mathrm{Cl} 46.0-51.6)$

Factors associated with PDPH:

Previous history of spinal anaesthesia and blood loss of greater than $500 \mathrm{mls}$ were significantly associated with post dural puncture headache. Patients who had analgesia given and those who took long to ambulate had higher risk of developing post dural puncture headache however this was marginally significant. Details are highlighted in Table 2 below.

Table 2: Factors associated with post dural puncture headache among women undergoing caesarean section at Mulago National Referral Hospital. 
Variables

Indication

Obstructed labour

$\mathrm{APH}$

CPD

Previous scar

ASA classification

Class 1

Class 2

Class 3 and above

Significant history

History of spinal

anaesthesia

History of PDPH

History of migraine

Hypertension

Chronic medication

Alcohol

Smoking

Anaesthesia

Anaesthetic officer

Resident

Anaesthesiologist

Additive drugs

Fentanyl

Morphine

Level of needle
520(40.4) 1

35(2.7)

1.1(0.6-2.2)

0.71

69(5.3)

1.4(0.8-2.4)

0.3

$346(26.9) \quad 1.1(0.8-1.4)$

0.67
0.13

0.79

$9(0.7)$

$0.9(0.2-3.3)$

0.85

$0.8(0.2-3.2)$

\begin{tabular}{lll} 
425(32.8) & $1.3(1.0-1.6)$ & $\mathbf{0 . 0 4}$ \\
\hline $138(10.7)$ & $1.6(1.1-2.3)$ & $\mathbf{0 . 0 1}$ \\
$21(1.6)$ & $2.3(0.9-6)$ & $\mathbf{0 . 0 9}$ \\
$6(0.5)$ & $1.2(0.8-1.7)$ & 0.31
\end{tabular}

126(9.7)

$0.9(0.8-1.1)$

0.4

$0.9(0.8-1.0)$

0.21

$1.3(1.0-1.6)$

0.04

0.01

12(0.9) 2.1(0.6-7.0) 0.22

$3(0.2)$

0.5(0.06-4.4)

0.49 
L3/L4

L4//5

Angle of needle insertion

Oblique

171(13.2)

Perpendicular

1123(86.8)

$0.9(0.6-1.3)$

0.51

Blood loss(millilitres)

$\leq 500$

$>500$

Analgesia given

No

Yes

Ambulate

Day 1

Day 2

Body mass index

Underweight

Normal

Overweight

obese

Morbid obesity
1046(80.8) 1

248(19.2) 2.1(1.1-4)
1.2(0.9-1.7) $\quad 0.19$

1 109(8.4) 1

$1,183(91.6) \quad 1.3(0.9-1.9)$ 1241(99.1) $10(0.8)$ 6(0.5) $\quad 1$ 290(23.1) $\quad 1(0.2-4.9) \quad 0.98$ 504(40.1) $\quad 0.9(0.2-4.8) \quad 0.93$ 318(25.3) $\quad 0.9(0.2-4.7)$

$140(11.1) \quad 0.9(0.2-4.4) \quad 0.86$
1

$0.03 \quad 2.2(1.1-4.2)$

0.02

$0.21 \quad 1.4(1.0-2.0)$ 1.4(1.0-2.0) $\quad 0.08$ 1

4.2(1.0-20.1) $\quad 0.07 \quad 4(0.9-17.7)$ 0.07

\section{Discussion}

Incidence of PDPH: Post dural puncture headache (PDPH) is the most reported complication that can occur following spinal anaesthesia. Several studies carried out across the globe have shown the incidence of PDPH to range from $1 \%$ to $75 \%$ ( 13 ) and $3 \%$ to $60 \%$ ( 10 ). From this study, we found an unexpectedly high incidence of PDPH among women undergoing caesarean section in Mulago National Referral Hospital for the period from July 2015 to February 2016. Despite this incidence being in accordance with the ranges reported above, it is the highest incidence reported in published studies in which relatively small needle gauges like 25 gauge Quincke needles were used( $12,14-18)$. This was twice that reported in a similar study done in Nairobi (24.4\%) (9). Studies have shown that using small gauge needles like the one used in this study is protective however we still found out a higher incidence 
of PDPH which is 1.5 times higher than reported by a study done in Kasr El aini teaching hospital in Cairo, Egypt using a bigger gauge needle (gauge 22) were the overall incidence was reported $32.58 \%(7)$.

These differences could be explained by the fact that in our study, we only recruited women due for emergency caesarean section who required immediate intervention without time for pre loading fluids or correcting fluid deficits. (19)

If a post dural puncture headache is to occur, it has been reported to occur in $90 \%$ of patients within the first 72 hours ( 13 ). True to this finding, most patients developed the PDPH within that time duration with a cumulative incidence of $31.8 \%$ however we had $23.7 \%$ of patients developing PDPH on the seventh day. This suggests presence factors out of hospital possibly contributing to the high incidence seen in our setting. Furthermore, when compared to studies that followed patients for only three days, (17) the cumulative incidence by day three in our study is still higher(8.7\% versus $31.8 \%)$. The difference in sample size could still account for this finding.

\section{Factors associated with post dural puncture headache in parturients in MNRH.}

Turnbull and Shepherd in 2003, named a number of factors that were associated with PDPH. Among these were needle size and design, operator skill and level of training, number of attempts, body posture, time to ambulation and fluids received. From studies assessing factors directly associated with PDPH, we considered factors that may contribute to PDPH in our setting taking into account the patient burden and hospital limitations. $(7,12,13,16,20)$.

The factors that were significantly associated with PDPH from this study were previous exposure to spinal anaesthesia and blood loss greater than 0.5 liters.

Women who lost more than 0.5 litres of blood during surgery were more likely to have PDPH compared to those who lost comparably smaller amounts of blood. This is novel as there is no published literature comparing the volume of blood lost intra operatively and development of post dural puncture headache.

Patients with previous exposure to spinal anaesthesia developed PDPH as compared to of women without previous exposure ( $53 \%$ vs. $46.8 \%$ respectively), $P$ value $=0.04$. This was consistent with findings from studies describing factors associated with $\operatorname{PDPH}(7-9,20-23)$. The exact mechanism by which this happens is not known.

\section{Conclusions}

The incidence of PDPH in our patients is the highest that has been reported in both developed and developing regions. The factors found to be associated with this high incidence included blood loss more than 0.5 liters and previous exposure.

\section{List Of Abreviations}


ASA, American Society of Anesthesiologist, MNRH Mulago National Referral and Teaching Hospital, PDPH post dural puncture headache, APH ante partum hemorrhage, CPD cephalo pelvic disproportion, BMI body mass index

\section{Declarations}

Ethical approval and consent to participate

This study was performed in accordance with the Good Clinical Practice (GCP) Guidelines, and the Declaration of Helsinki (24) Written informed consent was obtained from all participants that were capable of providing the consent. For the women below 18 years of age, both SOMREC and UNCST deemed these participants emancipated minor and gave informed written consent before they could be enrolled into the study. Risk analysis was carried out as part of protocol development. Ethical approval to conduct this study was obtained from the Makerere University School of Medicine Research and Ethics Committee (SOMREC) and the Uganda National Council for Science and Technology (UNCST). Informed consent process was strictly adhered to and confidentiality observed.

Consent to publish

Not applicable

Availability of data and materials

Data cannot be shared because relevant approvals from the institutions that participated are not in place. Competing Interests

The authors declare that they have no competing interests

Funding

This research did not receive any specific grant from funding agencies in public, commercial or not- forprofit sectors.

Acknowledgements

We are so grateful to the members of staff in the Departments of Anaesthesia and obstetrics and gynaecology of MNRH. We extend our thanks to the research team who helped in the collection of data and the patients who took part in this study. Lastly, to the Ugandan Ministry of Health through the HSSP project and Association of Anaesthesiologists of Great Britain and Ireland.

Authors' contributions

PN, AK and MTN conceived the research topic, which was furnished by KS. KS and JBK analysed data, drafted the manuscript, and made edits to the manuscript. PBN, collected the data, participated in 
developing the analysis plan, made contributions to edits of the draft manuscript. All the authors contributed to the development of the manuscript, have read and approved the final manuscript.

\section{References}

1. Dresner MR, Freeman JM. Anaesthesia for caesarean section. Best practice \& research Clinical obstetrics \& gynaecology. 2001;15(1):127-43.

2. King H-k, Ashley S, Brathwaite D, Decayette J, Daniel J. Adequacy of general anesthesia for cesarean section. Anesthesia \& Analgesia. 1993;77(1):83-8.

3. Tsen L, Pitner R, Camann W. General anesthesia for cesarean section at a tertiary care hospital 19901995: indications and implications. International journal of obstetric anesthesia. 1998;7(3):147-52.

4. Riley ET, Cohen SE, Macario A, Desai JB, Ratner EF. Spinal versus epidural anesthesia for cesarean section: a comparison of time efficiency, costs, charges, and complications. Anesthesia \& Analgesia. 1995;80(4):709-12.

5. Shahien R, Bowirrat A. Facial nerve paralysis and partial brachial plexopathy after epidural blood patch: a case report and review of the literature. Journal of pain research. 2011;4:39.

6. Sydow F-W. Geschichte der Lokal-und Leitungsanästhesie. Anaesthesie-historisch gesehen: Springer; 1987. p. 38-53.

7. Ali HM, Mohamed MY, Ahmed YM. Postdural puncture headache after spinal anesthesia in cesarean section: Experience in six months in 2736 patients in Kasr El aini teaching hospital-Cairo University. Egyptian Journal of Anaesthesia. 2014;30(4):383-6.

8. Turnbull DK, Shepherd D. Post-dural puncture headache: pathogenesis, prevention and treatment. British journal of anaesthesia. 2003;91(5):718-29.

9. Gisore E, Mung'ayi V, Sharif T. Incidence of post dural puncture headache following caesarean section under spinal anaesthesia at the Aga Khan University Hospital, Nairobi. East African medical journal. 2010;87(6):227-30.

10. Tinca C, Ciobotaru R, Voinescu D, Matei MN, Ciobotaru O, Tolan T. ORIGINAL STUDY POST-DURAL PUNCTURE HEADACHE.

11. Tinca C, Ciobotaru R, Voinescu D, Matei M, Ciobotaru O, Tolan T. POST-DURAL PUNCTURE HEADACHE. Annals of the University Dunarea de Jos of Galati: Fascicle: XVII, Medicine. 2014(1):87-91.

12. Jabbari A, Alijanpour E, Mir M. Post spinal puncture headache, an old problem and new concepts: review of articles about predisposing factors. Caspian Journal of Internal Medicine. 2013;4(1):595. 
13. Sachs A, Smiley R, editors. Post-dural puncture headache: The worst common complication in obstetric anesthesia. Seminars in perinatology; 2014: Elsevier.

14. Gisore E, Mung'ayi V, Sharif T. Incidence of post dural puncture headache following caesarean section under spinal anaesthesia at the Aga Khan University Hospital, Nairobi. East African medical journal. 2010;87(6):227-30.

15. Omole OB, Ogunbanjo GA. Postdural puncture headache: evidence-based review for primary care. South African Family Practice. 2015;57(4):241-6.

16. Shaikh JM, Memon A, Memon MA, Khan M. Post dural puncture headache after spinal anaesthesia for caesarean section: a comparison of $25 \mathrm{~g}$ Quincke, $27 \mathrm{~g}$ Quincke and $27 \mathrm{~g}$ Whitacre spinal needles. Journal of Ayub Medical College, Abbottabad : JAMC. 2008;20(3):10-3.

17. Siddiqui AS, Salim B, Hashemy N, Siddiqui SZ. Post-dural Puncture Headache After Spinal Anaesthesia for Caesarean Section. Journal of Surgery Pakistan (International). 2015;20:1.

18. Wu CL, Rowlingson AJ, Cohen SR, Michaels RK, Courpas GE, Joe EM, et al. Gender and post-dural puncture headache. Anesthesiology. 2006;105(3):613-8.

19. Bajwa SJS, Kulshrestha A, Jindal R. Co-loading or pre-loading for prevention of hypotension after spinal anaesthesia! a therapeutic dilemma. Anesthesia, Essays and Researches. 2013;7(2):155.

20. Deo G. Post Dural Puncture Headache. Journal of Chitwan Medical College. 2013;3(1):5-10.

21. Ansaloni L, Brundisini R, Morino G, Kiura A. Prospective, randomized, comparative study of Misgav Ladach versus traditional cesarean section at Nazareth Hospital, Kenya. World journal of surgery. 2001;25(9):1164-72.

22. Chohan U, Hamdani GA. Post dural puncture headache. JPMA The Journal of the Pakistan Medical Association. 2003;53(8):359-67.

23. Dutton DA. A 'postspinal headache' associated with incidental intracranial pathology. Anaesthesia. 1991;46(12):1044-6.

24. Carlson RV, Boyd KM, Webb DJ. The revision of the Declaration of Helsinki: past, present and future. British journal of clinical pharmacology. 2004;57(6):695-713. 